\title{
Simulating residential electricity and heat demand in urban areas using an agent-based modelling approach
}

\author{
Gonzalo \\ Bustos-Turu \\ Koen H. van Dam \\ Salvador Acha \\ Christos N. \\ Markides \\ Centre for Process Systems Engineering (CPSE) \\ Department of Chemical Engineering \\ Imperial College London, UK \\ \{gb1612, k.van-dam, salvador.acha06, c.markides, n.shah\}@ic.ac.uk
}

Nilay Shah

\begin{abstract}
Cities account for around $75 \%$ of the global energy demand and are responsible for $60-70 \%$ of the global greenhouse gasses emissions. To reduce this environmental impact it is important to design efficient energy infrastructures able to deal with high level of renewable energy resources. A crucial element in this design is the quantitative understanding of the dynamics behind energy demands such as transport, electricity and heat. In this paper an agent-based simulation model is developed to generate residential energy demand profiles in urban areas, influenced by factors such as land use, energy infrastructure and user behaviour. Within this framework, impact assessment of low carbon technologies such as plug-in electric vehicles and heat pumps is performed using London as a case study. The results show that the model can generate important insights as a decision support tool for the design and planning of sustainable urban energy systems.
\end{abstract}

Index Terms-Energy demand modelling, urban energy systems, agent-based simulation, sustainable cities, low carbon technologies

\section{INTRODUCTION}

More than half of the world's population currently live in urban areas [1] accounting for about $75 \%$ of the total energy consumption [2]. And according to some studies, this demand is related with $60-70 \%$ of the global greenhouse gases emissions [3]. In this context, it is important to understand the influencing factors of energy demand in cities so different sustainability measures can be assessed. In particular, the proper design of integration strategies for low carbon technologies in urban energy systems relies on an accurate spatial and temporal characterization of energy requirements.

The electrification of heat and transport leads to further interaction between city infrastructure systems as well as new opportunities for using renewable technologies. Moreover, these are typically somewhat flexible loads which means they can respond to the intermittent nature of (distributed) renewable energy. This system integration can present potential co-benefits such as an increase in systems reliability and performances, cost reductions and minimisation of environmental impacts [4]. However, there are some challenges related with the vulnerability and resilience of interdependent systems [5] and with the level of complexity in the analysis.

\begin{tabular}{|c|c|}
\hline \multicolumn{2}{|c|}{ NOMENCLATURE } \\
\hline \multicolumn{2}{|l|}{ Set } \\
\hline$k$ & Simulation time step \\
\hline$j$ & Urban zone \\
\hline$i$ & Plug-in electric vehicle (PEV) agent \\
\hline \multicolumn{2}{|c|}{ Variables } \\
\hline$o c c_{j k}$ & Urban zone occupancy [\%] \\
\hline $\operatorname{red}_{j k}$ & Residential electricity demand $[\mathrm{kW}]$ \\
\hline$r h d_{j k}$ & Residential heat demand $[\mathrm{kW}]$ \\
\hline $\operatorname{rhpd}_{j k}$ & Residential heat pump demand $[\mathrm{kW}]$ \\
\hline $\operatorname{soc}_{i k}$ & State of charge of PEV [\%] \\
\hline$d_{i k}$ & Distance traveled by a PEV $[\mathrm{km}]$ \\
\hline \multicolumn{2}{|c|}{ Parameters } \\
\hline$T_{k}^{i n}$ & Indoor temperature $\left[{ }^{\circ} \mathrm{C}\right]$ \\
\hline$T_{k}^{\text {out }}$ & Outdoor temperature $\left[{ }^{\circ} \mathrm{C}\right]$ \\
\hline$R F A_{j}$ & Residential floor area $\left[\mathrm{m}^{2}\right]$ \\
\hline$H L P_{j}$ & Heat loss parameter $\left[\mathrm{W} / \mathrm{m}^{2} \mathrm{~K}\right]$ \\
\hline$H H_{j}$ & Number of households \\
\hline$L_{b}$ & Electricity base load per household [kW] \\
\hline$L_{p}$ & Electricity peak load per household [kW] \\
\hline$H P A L_{i}$ & Heat pump adoption level [\%] \\
\hline $\mathrm{COP}_{k}$ & Heat pump coefficient of performance [\%] \\
\hline$E C R_{i}$ & PEV Energy consumption rate $[\mathrm{Wh} / \mathrm{km}]$ \\
\hline$B C_{i}$ & PEV battery capacity $[\mathrm{kWh}]$ \\
\hline chRate & PEV charging rate $[\mathrm{kW}]$ \\
\hline$\eta_{P E V}$ & PEV round-trip efficiency [\%] \\
\hline
\end{tabular}


In a distributed scale the characterisation of energy demands needs to consider the temporal and spatial elements at fine levels of detail. Energy demands present different requirements, spread in time and space, which are influenced not only by external factors such as weather, land use, sociodemographics, etc. but also by user behaviour. However, there has been a tendency in energy systems modelling research to neglect factors such as human behaviour and non-financial barriers in the analysis of demand for energy services and technology deployment and usage [6, 7].

Frequently employed to estimate transport demand using simulation models, activity-based modelling is relatively unexplored to gain insights in energy demands such as for heat and electricity at a district or city level. Authors in [8] found only four papers which focus on energy demand estimation in the built environment of which two ([9] and [10]) include bottom-up demand modelling, though they do not specifically focus on behaviour but rather use statistical samples, and are focused only on an individual dwelling level. In [11], an overview of modelling techniques for energy consumption is presented, highlighting the strengths and weaknesses of bottom-up and top-down approaches, but without including the agent-based modelling approach specifically.

Early work in this domain by [12] shows how socioeconomic data and home activities based on surveys can lead to daily load profiles. In [15] and in [16] activity-based energy demand profiles are simulated using time-use surveys data to estimate occupant activities. At a household level analysis, authors in [13] build their energy demand profiles in the residential sector from occupancy of the buildings, keeping in mind the occupants' socio-economic and demographic profiles to derive the activities that meet certain needs of the household. Similarly, in [14], daily activity schedules are used to simulate electricity and gas demands representing local geography and characteristics of the simulated household. The estimation is done performing a regression model with statistical energy consumption data, without considering the processes behind these demands.

For the case of bottom-up models, one of the main challenges is the estimation of occupant behaviour as one of the most influencing factors in the energy consumption [11]. In this work we present an integrated bottom-up modelling approach, using an agent-based simulation model in which different occupants' activity schedules can be incorporated to generate residential heat and electricity demand profiles, for different zones in an urban area. With these profiles, building occupancy as well as the residential energy consumption is simulated to evaluate the operational impact of different low carbon technologies such as plug-in electric vehicles (PEV) and heat pumps (HP).

\section{MODELLING FRAMEWORK}

An integrated modelling approach is developed to simulate energy demand in the residential sector. Using an agent-based simulation (ABS) model, different influencing factors are considered such as urban layout, land-use, socio demographic characteristics, energy infrastructure access, conversion technologies and user behaviour. These factors generate daily transport, electricity and heat demand profiles. Based on the model presented in [17], in this paper, the residential energy demands (electricity and heat) and the heat pump electricity consumption are included.

The model considers the urban area divided into different zones with some distinct socio demographic parameters. For each zone, an heterogeneous group of agents is generated using a synthetic population methodology [18]. Each agent is then associated with a different activity schedule, level of car ownership, working status, etc. so different trips can be generated. Once the simulation is initiated, different travel patterns are generated based on each agent's activity schedule. These travel behaviour will produce the PEV charging requirements and also the occupancy patterns that are used to estimate the residential energy demand profiles. These energy demands are also influenced by technical, infrastructural, environmental and behavioural factors, which will be detailed in the next sections.

\section{A. Electricity demand model}

The residential electricity demand $\operatorname{red}_{j k}$ for urban zone $j$ at simulation time step $k$ is generated taking into account the base and peak load, the number of households per zone and the occupancy profile generated from agent's activity schedules (see Eq. 1).

$$
\operatorname{red}_{j k}=H H_{j} \cdot\left[L_{b}+\left(L_{p}-L_{b}\right) \times o c c_{j k}\right]
$$

\section{B. Heat demand model}

The residential heat demand $r h d_{j k}$ is generated considering the difference between outdoor and indoor temperatures, the heat loss parameter for the residential floor area, and the occupancy profile, using Eq. 2. This approach is similar to the traditional heating degree day method, but here hourly data is used instead and occupancy is included in the calculation.

$$
r h d_{j k}=\left(T_{k}^{i n}-T_{k}^{o u t}\right) \times H L P_{j} \times R F A_{j} \times o c c_{j k} / 1000 \quad \text { Eq. } 2
$$

In the previous equation, $H L P_{j}$ is the heat loss parameter and $R F A_{j}$ the residential floor area (estimated based on the total residential footprint area and weighted average building height).

\section{Heat pump demand model}

Once the heat demand is estimated, the heat pump demand can be generated considering the coefficient of performance (COP) and adoption level of heat pumps, using the following expression:

$$
r h p d_{j k}=H P A L_{j} \times r h d_{j k} / C O P_{k}
$$

The $C O P_{k}$ is calculated for each time step depending on the external temperature. This effect is estimated based on the results presented in [19] for a set of commercial air-source heat pumps and are shown in Figure 1. The linear approximation shown in Eq. 4 is used to characterise the effect of outdoor temperature $T_{k}^{\text {out }}$ on the $C O P_{k}$.

$$
C O P_{k}=0.04627 \cdot T_{k}^{\text {out }}+3.03283
$$




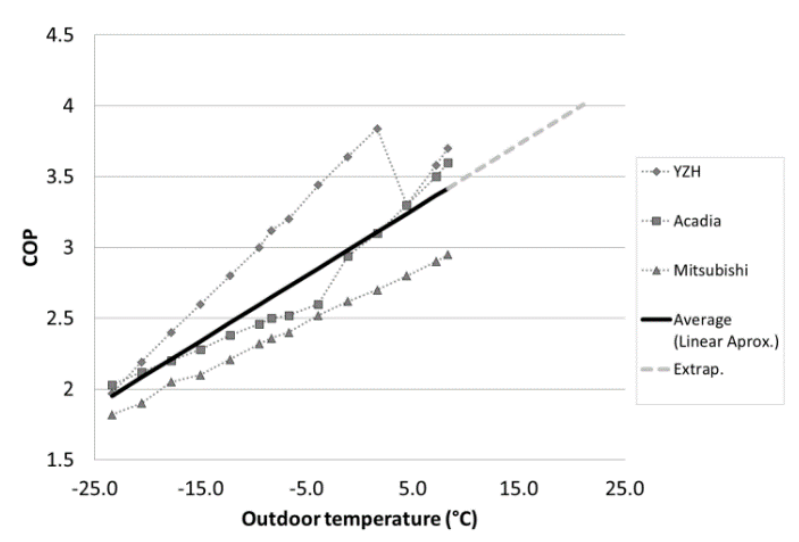

Figure 1. Effect of external temperature on the COP.

\section{Electric vehicle demand model}

The energy consumption of each individual PEV agent $i$ is determined by the discharging process given by Eq. 5 .

$$
\operatorname{soc}_{i k}=\left(\operatorname{soc}_{k-1}-\frac{d_{i k} \times E C R_{i}}{B C_{i} \times 1000}\right)
$$

Where $\operatorname{soc}_{i k}$ is the state of charge and $d_{i k}$ the distance traveled of agent $i$ at each time step $k$. Finally, $E C R_{i}$ represents the energy consumption rate for each PEV depending on its type (mini, small, medium). Details of this classification can be found in [20].

In the ABS model the level of access to different charging point are considered based on local authority plans and access to off-street parking facilities. When a PEV arrives to a site with access to a charging point, a charging process will start following the relation shown in Eq. 6

$$
\text { soc }_{i k}=\left(\text { soc }_{k-1}+\text { chRate }_{i} \times \eta_{P E V} \times \Delta k\right)
$$

Where chRate $_{i}$ is the charging power rate of the charging point or charging station where the agent $i$ is currently charging, $\eta$ the round-trip efficiency that includes the losses in the charging and discharging processes and $\Delta k$ is the time step. The specific charging rate will depend on the charging point type (i.e., normal, fast). Details of the representation of the charging infrastructure can be found in [20].

\section{CASE STUDY}

The case study is based on an urban area in London covering seven boroughs with a total area of $175 \mathrm{~km}^{2}$ (around $10 \%$ of Greater London). Each borough represents one individual zone without representing individual buildings (see Figure 2). Instead, land use distributions for each borough are considered to estimate residential, commercial and industrial areas. In this case study, only a $10 \%$ of the population is simulated, corresponding to 38,342 agents. It is assumed here all agents are vehicle drivers, and therefore pedestrians or public transport users are not considered. Among this population, two groups are considered: workers and nonworkers. The details about the socio demographic parameters, land use and building environment can be found in [17]. For this particular analysis, the height of buildings was extracted from [21], and for the heat loss parameter the average for UK $\left(3.2 \mathrm{~W} / \mathrm{m}^{2} \mathrm{~K}\right)$ was considered [22].

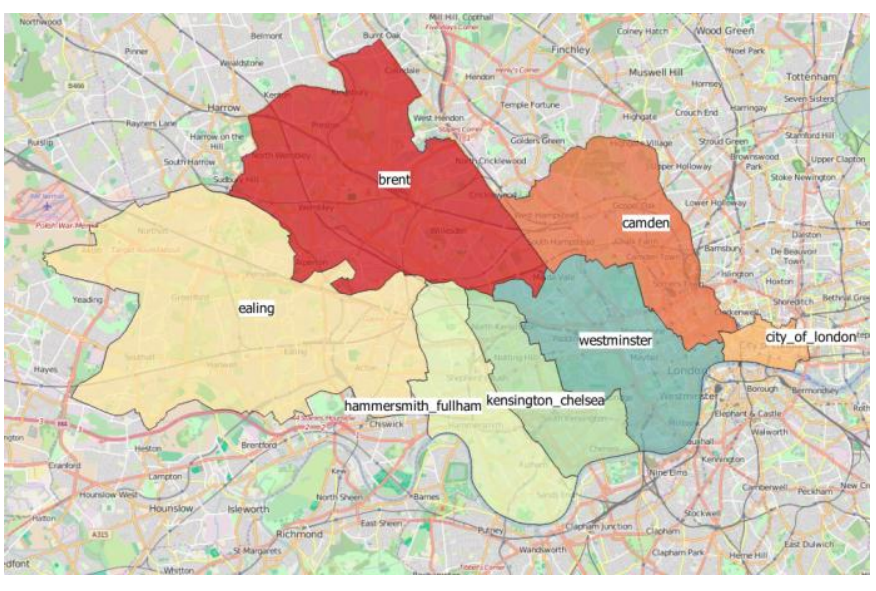

Figure 2. Map showing the simulated urban area in London, UK.

Using the urban area defined previously, a baseline scenario is simulated to estimate the residential electricity and heat demand profiles. In the case of the electricity this profile is calibrated with the base and peak load of typical load profiles for UK [24]. Next, a low carbon technology scenario is simulated, in which a $10 \%$ of adoption of PEVs and HPs is considered. The details about the PEV fleet and charging infrastructure parameters can be found in [20]. For the simulations two days were considered: one for winter and one for summer. The temperature profile used for these two days is based on hourly data available in [23] for a weather station located in Heathrow, London for 2014.

\section{RESUlTS}

For the baseline scenario, Figure 3 shows the electricity demand profile, compared with the average for a domestic unrestricted customer (profile class 1), based on [24]. Both curves present a similar trend, with two clear peaks in the morning and evening. In the case of the simulation, this evening peak occurs later than in the case of the typical profile. One possible explanation is the linear dependence of this demand and the zone's occupancy, neglecting the effect of the shared use of electrical appliances by occupants.

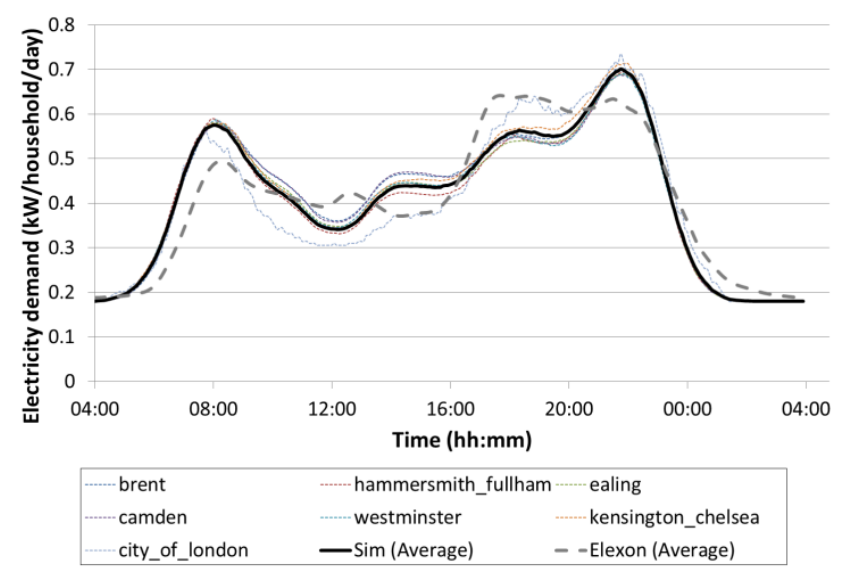

Figure 3. Electricity demand profile for baseline scenario. Simulation v/s typical UK profile. 


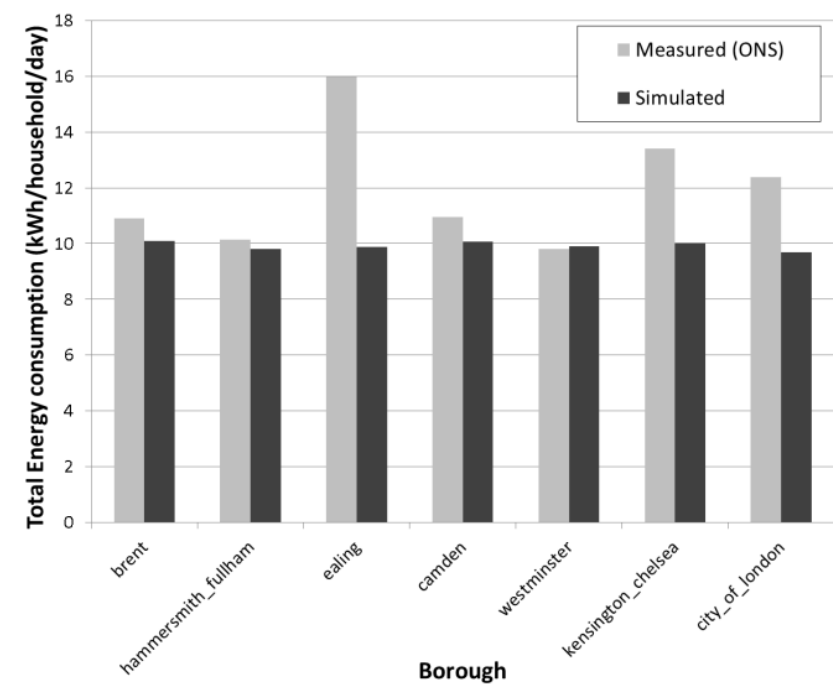

Figure 4. Aggregated daily electricity demand for baseline scenario. Simulation v/s ONS data.

In addition to the daily profile comparison, an aggregated value is calculated for an average consumption per household per day. Figure 4 shows the comparison between these aggregates for each borough with their corresponding measured energy demand based on national statistics [25]. In average the difference between the simulation and the statistical data is $14.9 \%$, with boroughs with significant difference, such as Ealing (38\%), Kensington and Chelsea $(25 \%)$, and City of London (21\%). One element that can be influencing this difference is the base and peak load used to calibrate the curves. In this model, only an average UK value was used and no variation between boroughs was included. Clearly, a more accurate description would be to use boroughspecific base and peak load values as input parameters, so a more realistic representation of the level of electrical appliances ownership can be included in the model.

In the case of heat demand, due to the lack of data publicly available for typical daily profiles in UK, it was not yet feasible to compare or calibrate the generated demand with real measurements. Figure 5 shows the daily heat demand for each zone, with the average for the whole urban area. It is interesting to note the similitude of this curve with the electricity demand, as the occupancy is one of the main influencing factors. Depending on the specific situation, this assumption can be underestimating the real demand as there could be cases where occupants keep the heating system running even if they are not in the property. This situation has to be evaluated in future work as it can represent an important case study for more intelligent control systems, particularly in energy systems in which smart meters will increasingly make such data available.

In Figure 6 the effect of the outdoor temperature in the heat demand is represented for different seasons. It is important to note these temperature profiles represent the three months average for each season (winter and summer) and therefore the real level of temperature variability is smoothed.

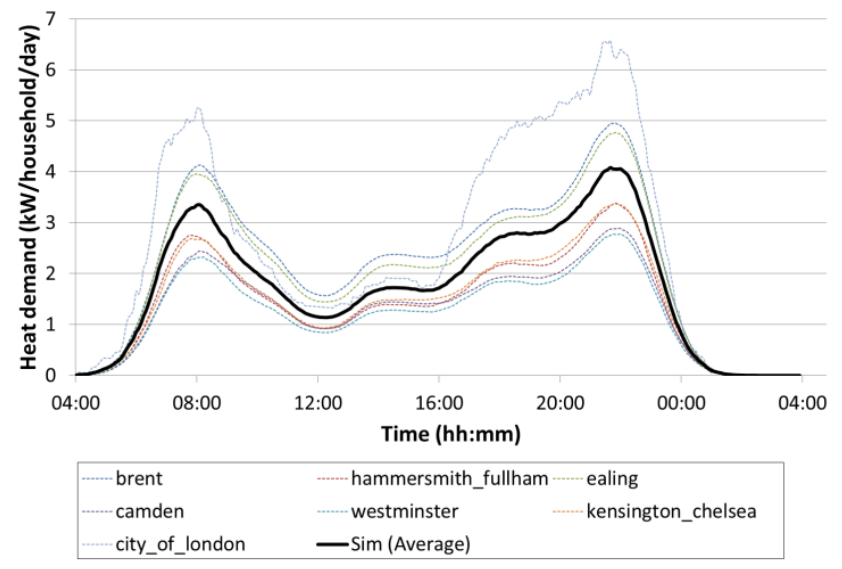

Figure 5. Heat demand profile for baseline scenario.

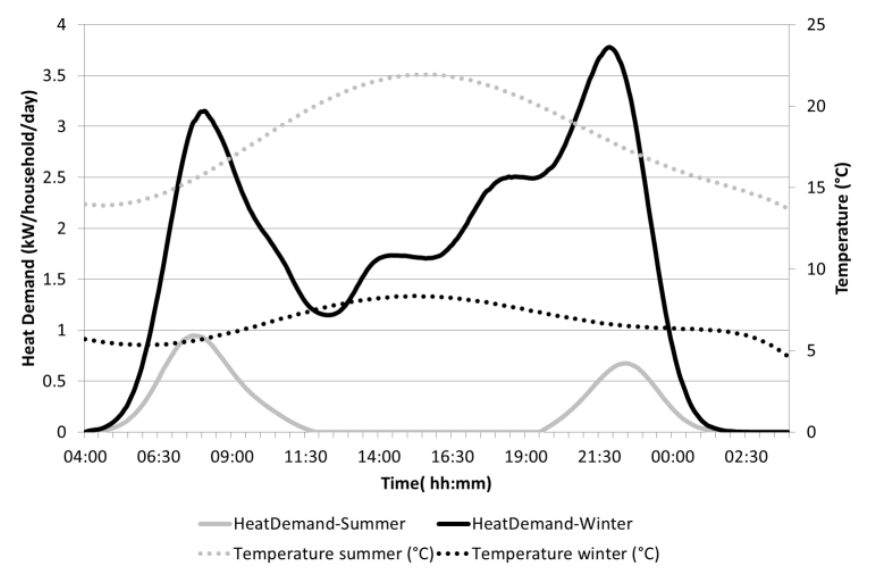

Figure 6. Heat demand profile and outdoor temperature for baseline scenario for different seasons.

Analogous to the case of electricity demand, the total annual heating demand is also compared with the statistical data. For the sake of comparison, the total gas consumption extracted from [25] was transformed to heat demand assuming only individual regular gas boilers with an $80.3 \%$ efficiency [26]. Figure 7 shows that in general the heat demand is underestimated in the simulation, with an average difference of $15 \%$ with respect to the statistical data. As previously stated, one possible explanation of this underestimation is the assumption that heat demand is strongly influenced by the active occupancy. This assumption would represent an ideal scenario in which users do not make use of any heating system while they are away from their homes. Based on this discussion, it is clear that a more detailed analysis of the impact of user's behaviour in the heat energy requirements needs to be carried out in future work. 


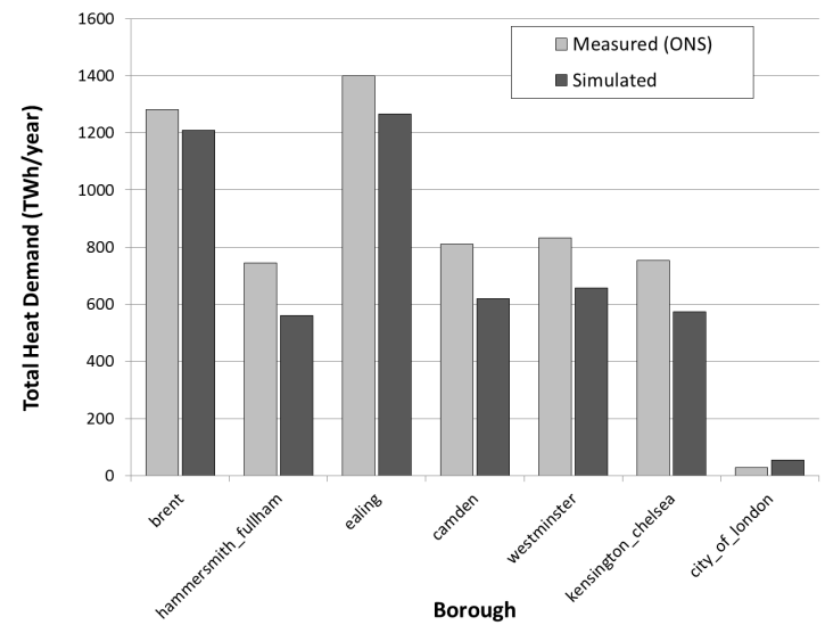

Figure 7. Aggregated annual gas demand for baseline scenario. Simulation v/s ONS data.

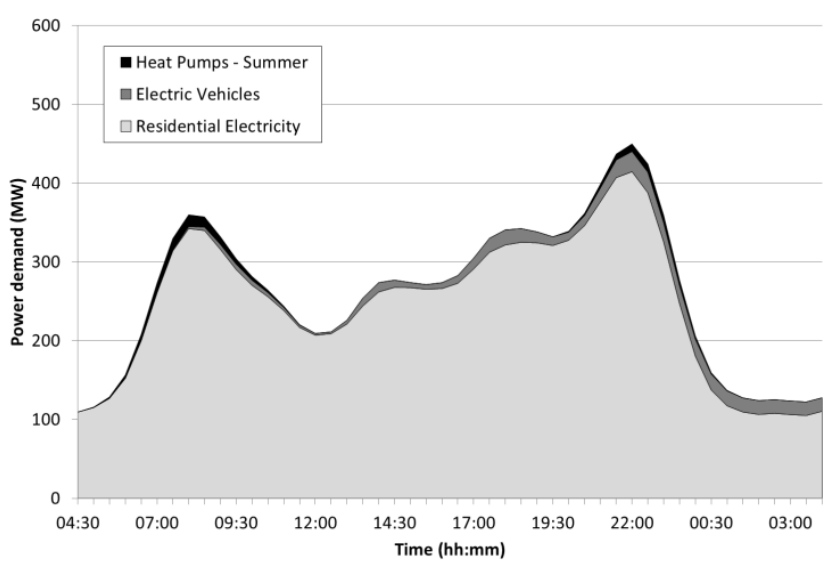

Figure 8. Electricity demand profile for low carbon technology scenario, for summer season.

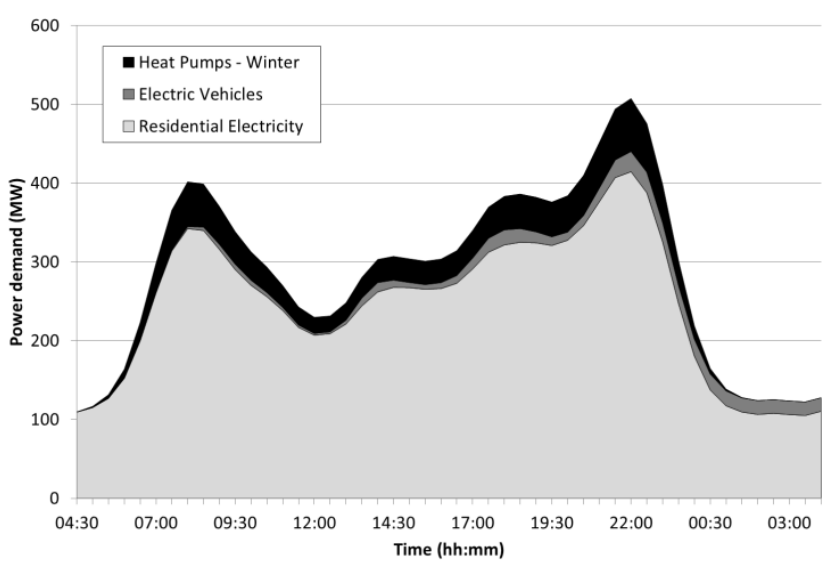

Figure 9. Electricity demand profile for low carbon technology scenario, for winter season.
Finally, Figure 8 and Figure 9 show the results of the low carbon technology scenario. In these figures the additional electricity demand of PEVs and HPs are added on top of the baseline electricity demand, so the impact of these technologies can be visualised. It is clear from the results that the impacts will have a seasonal dependence, with winter being the most critical period of the year. During winter peak times, the electricity demand of heat pumps can represent up to $17 \%$ of the baseline residential electricity demand. On the other hand, the electricity demand from PEVs can represent up to $16 \%$ during low demand periods (midnight), and only a $6 \%$ during the peak load periods (around 22:00) for both seasons.

\section{CONCLUSIONS AND FUTURE WORK}

In this work, a novel agent-based simulation model is developed to generate from a bottom-up perspective different energy demand profiles associated with the residential sector. Within this modelling framework, the different aspects of the energy demand can be incorporated. The model is tested with real data for an urban area in London, UK, and the results are compared with statistical data. Results show that the simulation model can reproduce the main trends of real energy demand statistics, allowing the evaluation of different low carbon technologies scenarios at system level.

Some of the future work was envisaged in the analysis of the different results. For example, a more detailed calibration needs to be done considering spatial specific parameters such as base and peak loads. Also, more sophisticated user behaviour scenarios can be developed for a deeper assessment of different demand side management strategies. These operational policies could present multiple objectives such as peak load and infrastructure congestion management, costs and $\mathrm{CO}_{2}$ emissions reductions, among others.

Finally, the spatial representation of energy networks (heat and electricity) can be incorporated in the model so more comprehensive planning and investment allocation analysis can be performed in supporting policy makers, urban planners and energy system operators keeping system level demands into account while also able to evaluate impact on individual households.

\section{ACKNOWLEDGMENT}

The authors would like to acknowledge CONICYT's Becas Chile scholarship program and the RCUK's Digital City Exchange project (EP/I038837/1) for their support.

\section{REFERENCES}

[1] United Nations, "World Urbanization Prospects: The 2014 Revision, Highlights," Department of Economic and Social Affairs, Population Division2014.

[2] GEA, Global Energy Assessment - Toward a Sustainable Future. Cambridge University Press, Cambridge, UK and New York, NY, USA and the International Institute for Applied Systems Analysis, Laxenburg, Austria, 2012.

[3] UN-HABITAT, "Cities and climate change: global report on human settlements," 2011.

[4] B. Kroposki, B. Garrett, S. Macmillan, B. Rice, C. Komomua, M O'Malley, et al., "Energy Systems Integration, A Convergence of Ideas," NREL2012. 
[5] G. Fu, R. Dawson, M. Khoury, and S. Bullock, "Interdependent networks: vulnerability analysis and strategies to limit cascading failure," The European Physical Journal B, vol. 87, pp. 1-10, 2014/07/01 2014.

[6] S. Pfenninger, A. Hawkes, and J. Keirstead, "Energy systems modeling for twenty-first century energy challenges," Renewable and Sustainable Energy Reviews, vol. 33, pp. 74-86, 2014.

[7] B. K. Sovacool, S. E. Ryan, P. C. Stern, K. Janda, G. Rochlin, D. Spreng, et al., "Integrating social science in energy research," Energy Research \& Social Science, vol. 6, pp. 95-99, 3// 2015.

[8] J. Keirstead, M. Jennings, and A. Sivakumar, "A review of urban energy system models: Approaches, challenges and opportunities," Renewable and Sustainable Energy Reviews, vol. 16, pp. 3847-3866, 2012.

[9] C. Koroneos and G. Kottas, "Energy consumption modeling analysis and environmental impact assessment of model house in Thessaloniki-Greece," Building and Environment, vol. 42, pp. 122$138,1 / / 2007$.

[10] M. Karagiorgas, T. Tsoutsos, and A. Moiá-Pol, "A simulation of the energy consumption monitoring in Mediterranean hotels: Application in Greece," Energy and Buildings, vol. 39, pp. 416-426, 4// 2007.

[11] L. G. Swan and V. I. Ugursal, "Modeling of end-use energy consumption in the residential sector: A review of modeling techniques," Renewable and Sustainable Energy Reviews, vol. 13, pp. $1819-1835,10 / / 2009$.

[12] A. Capasso, W. Grattieri, R. Lamedica, and A. Prudenzi, "A bottom-up approach to residential load modeling," Power Systems, IEEE Transactions on, vol. 9, pp. 957-964, 1994.

[13] T. Zaraket, B. Yannou, Y. Leroy, S. Minel, and E. Chapotot, "An occupant-based energy consumption model for user-focused design of residential buildings," Journal of Mechanical Design, pp. 1-11, 201504-01 2015.

[14] J. Keirstead and A. Sivakumar, "Using Activity-Based Modeling to Simulate Urban Resource Demands at High Spatial and Temporal Resolutions," Journal of Industrial Ecology, vol. 16, pp. 889-900, 2012.
[15] R. Subbiah, K. Lum, A. Marathe, and M. Marathe, "Activity based energy demand modeling for residential buildings," in Innovative Smart Grid Technologies (ISGT), 2013 IEEE PES, 2013, pp. 1-6.

[16] J. Widén, A. Molin, and K. Ellegård, "Models of domestic occupancy, activities and energy use based on time-use data: deterministic and stochastic approaches with application to various building-related simulations," Journal of Building Performance Simulation, vol. 5, pp. 27-44, 2012/01/01 2012.

[17] G. Bustos-Turu, K. van Dam, S. Acha, and N. Shah, "Integrated planning of distribution networks: interactions between land use, transport and electric vehicle charging demand," presented at the 23rd International Conference on Electricity Distribution, Lyon, France, 2015.

[18] K. H. van Dam, G. Bustos-Turu, and N. Shah, "A methodology for simulating synthetic populations for the analysis of socio-technical infrastructures," in The Eleventh Conference of the European Social Simulation Association (ESSA), Groningen, NL, 2015.

[19] Caneta Research Inc, "Heat Pump Characterization Study " 2010

[20] G. Bustos-Turu, K. van Dam, S. Acha, and N. Shah, "Estimating Plugin Electric Vehicle Demand Flexibility through an Agent-Based Simulation Model," presented at the 5th IEEE PES Innovative Smart Grid Technologies (ISGT) European 2014 Conference, Istanbul, Turkey, 2014.

[21] Digimap. (2015). Digimap Resource Centre. Available: http://digimap.edina.ac.uk/

[22] J. Palmer and I. Cooper, "United Kingdom housing energy fact file: 2013," 2014.

[23] Met Office. (2012). Met Office Integrated Data Archive System (MIDAS) Land and Marine Surface Stations Data (1853-current).

[24] Elexon. (2015). Profiling. Available: https://www.elexon.co.uk/reference/technical-operations/profiling/

[25] Office for National Statistics. (2015). Neighbourhood Statistics. Available: http://www.neighbourhood.statistics.gov.uk/dissemination/

[26] DECC, "In-situ monitoring of efficiencies of condensing boilers and use of secondary heating," 2009. 